\title{
Novel host-specific iron acquisition system in the zoonotic pathogen Vibrio vulnificus
}

\author{
David Pajuelo, ${ }^{1}$ Chung-Te Lee, ${ }^{2}$ Francisco J. Roig, ${ }^{1}$ \\ Lien-I. Hor ${ }^{2,3}$ and Carmen Amaro ${ }^{1 *}$ \\ ${ }^{1}$ Estructura de Investigación Interdisciplinar en \\ Biotecnología y Medicina (ERI BIOTECMED), \\ Department of Microbiology and Ecology, University of \\ Valencia, Dr. Moliner, 50, Valencia 46100, Spain. \\ ${ }^{2}$ Department of Microbiology and Immunology, Institute \\ of Basic Medical Sciences, Tainan 701, Taiwan. \\ ${ }^{3}$ College of Medicine, National Cheng-Kung University, \\ Tainan 701, Taiwan.
}

\section{Summary}

Vibrio vulnificus is a marine bacterium associated with human and fish (mainly farmed eels) diseases globally known as vibriosis. The ability to infect and overcome eel innate immunity relies on a virulence plasmid (pVvbt2) specific for biotype 2 (Bt2) strains. In the present study, we demonstrated that pVvbt2 encodes a host-specific iron acquisition system that depends on an outer membrane receptor for eel transferrin called Vep20. The inactivation of vep20 did not affect either bacterial growth in human plasma or virulence for mice, while bacterial growth in eel blood/ plasma was abolished and virulence for eels was significantly impaired. Furthermore, vep20 is an ironregulated gene overexpressed in eel blood during artificially induced vibriosis both in vitro and in vivo. Interestingly, homologues to vep20 were identified in the transferable plasmids of two fish pathogen species of broad-host range, Vibrio harveyi (pVh1) and Photobacterium damselae subsp. damselae (pPHDD1). These data suggest that Vep20 belongs to a new family of plasmid-encoded fish-specific transferrin receptors, and the acquisition of these plasmids through horizontal gene transfer is likely positively selected in the fish-farming environment. Moreover, we propose Ftbp (fish transferrin binding proteins) as a formal name for this family of proteins.

Received 1 October, 2014; revised 8 January, 2015; accepted 13 January, 2015. *For correspondence. E-mail carmen.amaro@uv.es; Tel. (+00) 349635431 04; Fax: (+00) 34963544570.

\section{Introduction}

Vibrio vulnificus is a multi-host pathogen from marine and estuarine ecosystems located in temperate, tropical and subtropical areas. In these ecosystems, the pathogen survives in the planktonic form or associated with the skin surface and intestine of aquatic animals and is also present in oysters and other filtering organisms, particularly during warm months (Hor et al., 1995; Pfeffer et al., 2003; Jones and Oliver, 2009). From these reservoirs, the pathogen can accidentally infect humans or fishes, causing diseases with multiple pathological presentations collectively called 'vibriosis' (Dechet et al., 2008; Jones and Oliver, 2009).

Human cases of vibriosis, such as primary sepsis, severe wound infections or secondary sepsis, sporadically occur after raw seafood ingestion, contact with contaminated-water/animal or spread from the skin to the blood respectively (Bullen et al., 1991; Horseman and Surani, 2011). Interestingly, the probability of death by sepsis significantly increases in patients presenting high levels of iron in the blood (Bullen et al., 1991; Hor et al., 2000). Fish vibriosis was discovered in farmed eels and further described in wild eels and other farmed-fish species (Biosca et al., 1991; Fouz et al., 2000; Pederssen et al., 2008). The disease occurs as outbreaks of a haemorrhagic septicaemia with a high probability of death, regardless of the iron levels in the blood. Fish-virulent strains, collectively called biotype 2 (Bt2), harbour a virulence plasmid ( $p V v B t 2$ ) that confers resistance to the eel innate immunity through unknown mechanisms (Lee et al., 2008; Valiente et al., 2008). Interestingly, the Bt2 strains belonging to serovar $E$ are zoonotic because these are associated with vibriosis in humans, following manipulation of diseased fishes (Amaro and Biosca, 1996; Haenen et al., 2014).

Mammals and fish share most innate defence mechanisms, including iron starvation (known as nutritional immunity). In fish and mammals, iron binds to host proteins, such as transferrin (Tf) or haemoglobin $(\mathrm{Hb}) /$ hemin $(\mathrm{Hm})$, and is unavailable for bacteria, unless they harbour high-affinity acquisition systems that successfully compete with host proteins for iron. Vibrio vulnificus possess two host-non-specific iron-uptake systems involved in virulence, one system depends on the 
siderophore vulnibactin and its receptor VuuA, and the other system depends on the haem receptor HupA (Biosca et al., 1996; Litwin and Byrne, 1998; Pajuelo et al., 2014). Notably, a second haem receptor, HutR, has been described, but this receptor is not involved in virulence (Pajuelo et al., 2014). Interestingly, the inactivation of both iron-uptake systems through mutations in the genes encoding the receptors VuuA and HupA completely abolishes the virulence for mice, but not the virulence for eels, suggesting the existence of a third, likely hostspecific, iron-uptake system in eels (Pajuelo et al., 2014). Furthermore, a candidate gene for this third system, vep20, has been identified using the FURTA (ferric uptake regulator titration assay) in pVvBt2 (Pajuelo et al., 2014). The vep20 gene is putatively controlled by the transcriptional regulator Fur through direct binding at a regulatory region in the promoter, called Furbox, and was annotated as a putative receptor for $\mathrm{Tf} / \mathrm{Hb} / \mathrm{Hm}$ based on low homology ( $29 \%$ of identity) with TbpA, the human Tf receptor in Neisseria (Pajuelo et al., 2014).

The aim of the present study was to demonstrate the biological function of Vep20 under the hypothesis that this protein is involved in host-specific iron uptake. To this end, we obtained a single vep20 mutant, the corresponding complemented strain and a triple mutant deficient in vep20, vuuA and hupA. Together with the wild-type strain, these bacteria were tested in a series of selected in vitro and in vivo assays using eels and mice as animal models. Moreover, we examined the phylogeny of vep20 and related genes within the Vibrio species to better understand the emergence of the zoonotic clonal complex within $V$. vulnificus.

\section{Results}

Vep20 is an iron-regulated outer membrane protein (IROMP)

Preliminary analysis suggests that Vep20 is an IROMP. Thus, according to Pfam, PsortB and SecretomeP, Vep20 is an $84 \mathrm{kDa}$ (741 amino acids) outer membrane (OM) receptor protein with two conserved functional domains: a $\beta$-barrel-TonB-dependent domain, which forms a channel across the OM, and a plug domain, which acts as a gate to facilitate or prevent ligand entry through the channel. In addition, Pajuelo et al. (2014) also suggested that Vep20 is under Fur control. To confirm that Vep20 is an IROMP, the $\mathrm{OM}$ proteins of the wild type and derivative strains ( $\Delta$ vep20, cvep20) were extracted from cultures grown in the absence and presence of iron, followed by immunostaining with antibodies against rVep20 (Fig. 1A). Vep20 was positively identified in the OM extract from the wild-type strain (Fig. 1B) but only when grown under iron restriction [CM9 plus $40 \mu \mathrm{M}$ iron-free human apotransferrin (apo-Tf) or a $40 \%$ of eel plasma] (Fig. 1A and
A
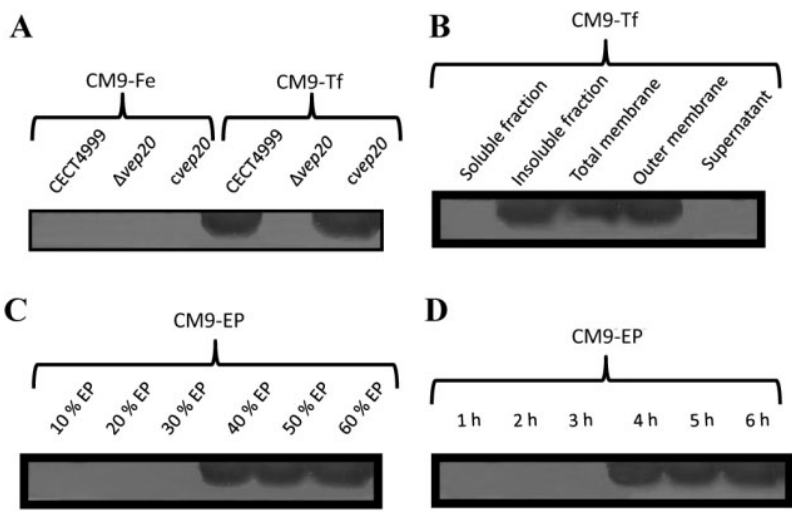

D

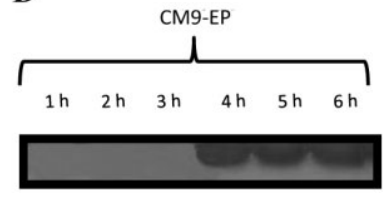

Fig. 1. Detection of Vep20 using Western blot analysis. A. Expression of Vep20 in the presence $(\mathrm{Fe})$ or absence (human apo-Tf) of iron.

B. Cellular location of Vep20 protein.

C. Expression of Vep20 protein in CM9 supplemented with different $\%$ of eel plasma.

D. Time course of Vep20 expression in CM9 supplemented with $50 \%$ eel plasma.

C), confirming that Vep20 is an IROMP. In addition, Vep20 was detected in $\mathrm{OM}$ extract after $4 \mathrm{~h}$ of incubation in CM9-EP (Fig. 1D). As expected, the mutant did not produce Vep20 under any of the assayed conditions (Fig. 1A). The molecular weight of Vep20, estimated using SDS-PAGE, was similar to that predicted through in silico analysis (approximately 80 versus $84 \mathrm{kDa}$ ).

\section{Vep20 is a host-specific virulence factor involved in} eel invasion

Compared with the wild type and the complemented strain, $\Delta$ vep20 did not show significant differences in virulence for i.p. (intraperitoneal)-injected mice, while virulence for i.p.-injected eels was dramatically impaired (Table 1). Furthermore, the inactivation of vep20 completely abolished virulence for eels when administered through the natural route of infection, i.e. immersion in a bacterial-infected bath (Table 1). Previous studies have shown that the hupA and vuuA double mutant (the receptors for vulnibactin and $\mathrm{Hm}$ ) was avirulent for mice but retained some degree of virulence for i.p.injected eels (Pajuelo et al., 2014) (Table 1). We obtained the triple mutant strain $\triangle$ hupA $\Delta$ vuuA $\Delta$ vep20 to determine whether vep20 influenced this remaining virulence. As expected, the triple mutant completely lost virulence for eels when administered through i.p. injection (Table 1).

The results of virulence assays revealed that Vep20 is a host-specific virulence factor; thus, we tested whether vep20 played a role in the invasion of internal organs using an in vivo colonization and invasion assay as previously described (Lee et al., 2013). Although 
Table 1. Virulence, siderophore production and growth in the presence of plasma and human holo-transferrin.

\begin{tabular}{|c|c|c|c|c|c|c|c|}
\hline \multirow[b]{3}{*}{ Strains } & \multicolumn{3}{|c|}{ Virulence $\left(\mathrm{LD}_{50}\right)^{\mathrm{a}}$} & \multirow{2}{*}{\multicolumn{2}{|c|}{$\begin{array}{l}\text { Growth in fresh } \\
\text { plasma from }\end{array}$}} & \multirow{3}{*}{$\begin{array}{l}\text { Growth with } \\
\text { human holo-Tf } \\
(\mathrm{mm})^{c}\end{array}$} & \multirow{3}{*}{$\begin{array}{l}\text { Minimal } \\
\text { stimulatory } \\
\text { concentration } \\
\text { of } \mathrm{Hm}(\mu \mathrm{M})^{\mathrm{d}}\end{array}$} \\
\hline & \multirow[b]{2}{*}{ Mice } & \multicolumn{2}{|c|}{ Eels } & & & & \\
\hline & & i.p. & Bath & Humans & Eels & & \\
\hline СЕСТ4999 & $3.2 \times 10^{2}$ & $2.1 \times 10^{2}$ & $4.4 \times 10^{6}$ & 151.3 & 141.26 & $17.3 \pm 2.8$ & 0.1 \\
\hline$\Delta$ vep20 & $8.6 \times 10^{2}$ & $4 \times 10^{6}$ & $>10^{8}$ & 157.48 & 0.93 & $18.3 \pm 2.3$ & 0.1 \\
\hline cvep20 & $2.6 \times 10^{2}$ & $3 \times 10^{2}$ & $3.6 \times 10^{6}$ & 114.10 & 113.07 & ND & 0.1 \\
\hline$\Delta v e p 20 \Delta h u p A \Delta v u u A$ & ND & $>10^{7}$ & $>10^{8}$ & ND & ND & ND & 0.1 \\
\hline$\Delta v u u A \Delta h u p A^{\mathrm{e}}$ & $>10^{7}$ & $7.4 \times 10^{5}$ & $>10^{8}$ & 3.73 & 4.8 & ND & 0.1 \\
\hline
\end{tabular}

a. $L D_{50}$ for mice was determined using the iron-overloaded model (Amaro et al., 1994). $L D_{50}$ is expressed as cfu per gr in case of i.p. injection and cfu per ml in case of bath infection (Amaro et al., 1995).

b. Ratio between final and initial bacterial counts on TSA-1 plates after $4 \mathrm{~h}$ of incubation in fresh plasma.

c. Diameter of growth halo in $\mathrm{mm}$ around Tf-discs (soaked in a solution of human holo-Tf $1 \mathrm{mM}$ ) placed on CM9A-E plates previously inoculated with $100 \mu \mathrm{l}$ of an overnight culture in CM9.

d. Minimum concentration in $\mu \mathrm{M}$ of bovine $\mathrm{Hm}$ in $\mathrm{CM} 9$ supplemented with $100 \mu \mathrm{M}$ of EDDHA that stimulated growth.

e. Data from Pajuelo et al. (2014).

ND, not done.

$\Delta$ vep20 colonized the gills of waterborne-infected eels, establishing a population similar in size to the wild-type strain, $\Delta$ vep20 was unable to invade the bloodstream and spread efficiently to the remaining internal organs (liver, head kidney and spleen) (Fig. 2). Thus, $\Delta$ vep20 was not recovered from the blood and was only recovered from the liver and head kidney at $24 \mathrm{~h}$ post-infection in numbers significantly lower than those of the wild-type strain (Fig. 2).

\section{Vep20 is involved in resistance to the eel innate immunity}

To determine whether Vep20 plays a role in survival in blood, wild type and derivative strains were incubated in fresh eel blood, a suspension of specific eel blood cells (erythrocytes or granulocytes) or fresh eel plasma.

As shown in Fig. 3, the growth of $\Delta$ vep20 was significantly impaired in eel plasma and eel blood but not in
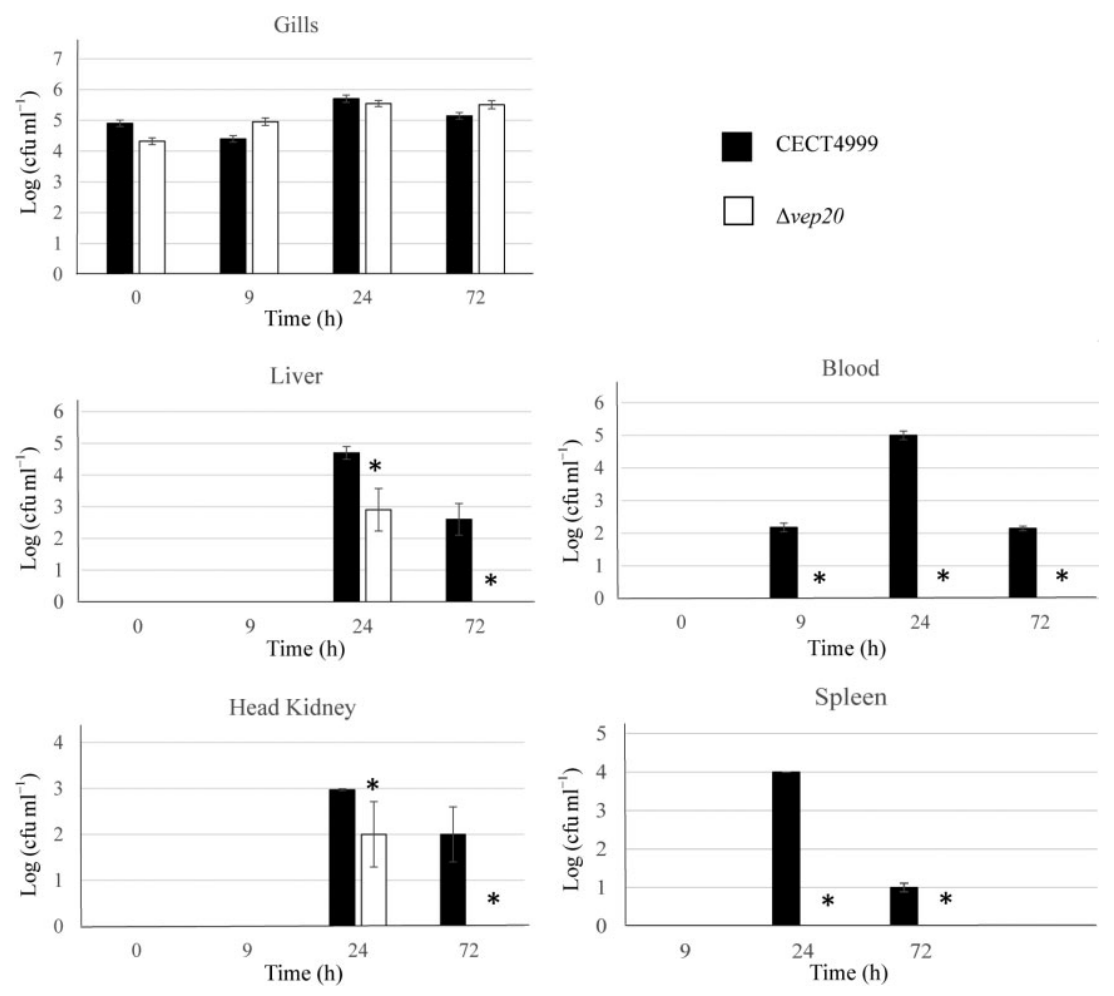

Fig. 2. V. vulnificus-eel in vivo assays. Eel colonization and invasion assays. The eels were bath infected with the wild-type strain (CECT4999) or $\Delta$ vep20 mutant at a dose of $10^{6} \mathrm{cfu} \mathrm{ml}^{-1}$ for $1 \mathrm{~h}$. Subsequently, the bacterial colonization in external (gills) and internal (blood, liver, head kidney and spleen) organs was measured as bacterial counts (cfu per g) at $0,9,24$ and $72 \mathrm{~h}$ post-challenge. The asterisks indicate significant differences in bacterial counts between the mutant and wild-type strains $(P<0.05)$.

(C) 2015 Society for Applied Microbiology and John Wiley \& Sons Ltd, Environmental Microbiology 


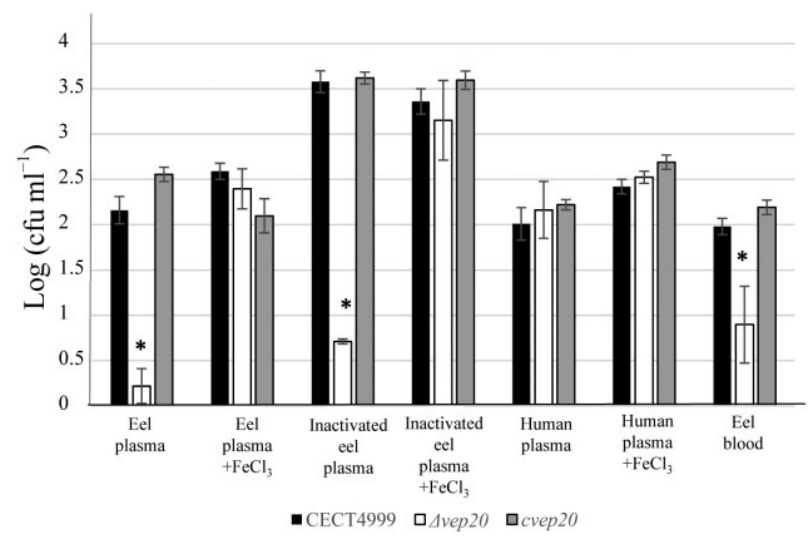

Fig. 3. Bacterial growth in plasma and blood. The bacterial growth of $V$. vulnificus strains, expressed as $\log _{10}$ units cfu $\mathrm{ml}^{-1}$, was measured at $4 \mathrm{~h}$ after incubation under different conditions. The asterisks indicate significant differences in growth between the mutant and wild-type strains $(P<0.05)$.

human plasma, confirming that Vep20 influences hostspecific growth in blood. To determine the inhibition in growth-reflected complement activity and/or iron sequestration via Tf in the eel blood, complement was heat inactivated, and eel plasma was supplemented with iron. The inactivation of eel complement did not affect bacterial growth, while iron supplementation abolished the inhibitory effect of eel plasma or heated eel plasma on the mutant strain (Fig. 3). Moreover, vep20 expressed in trans from a plasmid restored growth under all the tested conditions (Fig. 3). Thus, Vep20 is essential for the growth of this strain in eel blood and plasma but not in human plasma.

To find out whether Vep20 has a role in the interaction with eel cells, the wild type and $\Delta v e p 20$ were grown in presence of eel erythrocytes and phagocytes (granulocytes). Wild type and mutant Vibrio strains resist phagocytosis and destroy the monolayer of phagocytes in less than 90 min, generating similar total bacterial counts [from approximately $1 \times 10^{5}$ colony-forming units (cfu) per well at time 0 to approximately $1 \times 10^{6} \mathrm{cfu}$ per well after $90 \mathrm{~min}$ ] (Supporting Information Fig. S1A). No bacteria were detected in the surviving phagocytes (bacterial counts below the detection limit) (Supporting Information Fig. S1B). In addition, both strains destroyed erythrocytes in less than 90 min without significant differences in bacterial counts (Supporting Information Fig. S2 and data not shown). These results confirm that Vep20 is not involved in interactions with eel erythrocytes or resistance to phagocytosis.

vep20 is transcribed in vitro and in vivo

An increase in vep20 expression was observed in vitro in bacteria grown under iron-restricted con- ditions using either chemical (ethylenediamine-di-[ohydroxyphenylacetic or EDDHA) or biological (human apo-Tf or human plasma/eel plasma) chelators (Fig. 4A). vep20 expression in human and eel plasma was abolished when $\mathrm{FeCl}_{3}$ was added at 20 and $200 \mu \mathrm{M}$ concentrations respectively (Fig. 4A). We also examined the relationship between growth and gene expression by comparing the fold induction of vep20 with the growth curve of the wild-type strain under ironrestricted conditions (human apo-Tf or fresh eel plasma). As shown in Supporting Information Fig. S3, both parameters were associated with an increase in the transcript/RNA levels of vep20 at the beginning of the log phase, achieving a maximum just prior to the
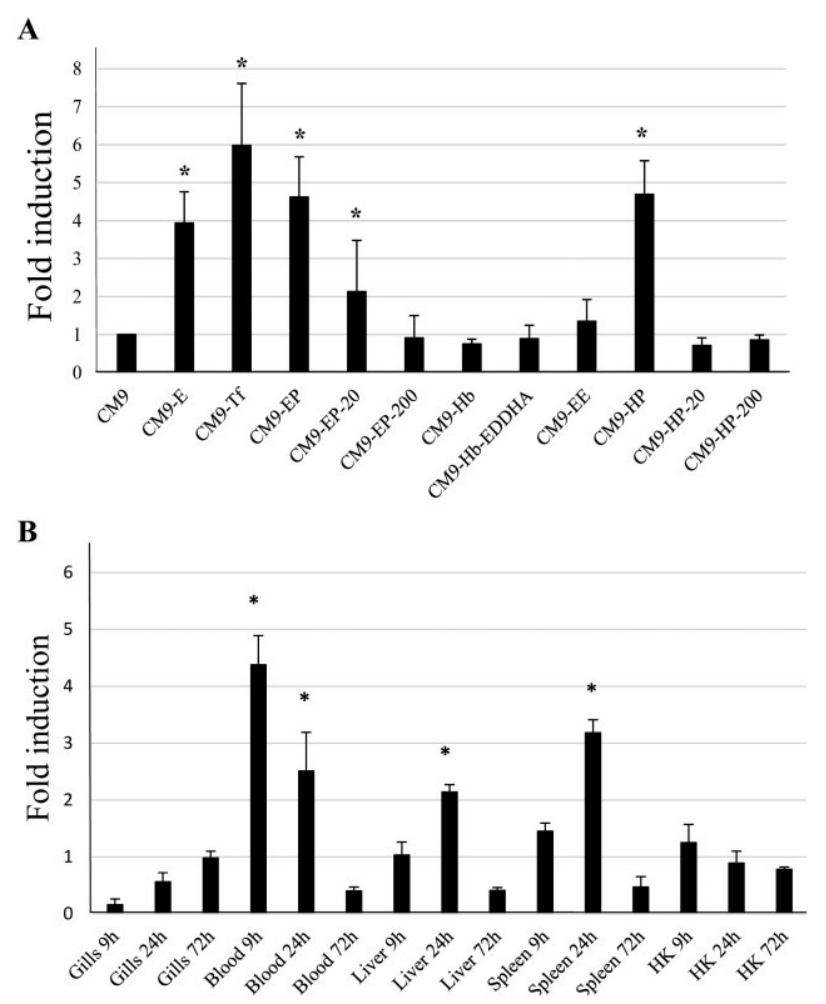

Fig. 4. Transcript/RNA level of vep20 in vitro estimated using qRT-PCR.

A. Transcript/RNA levels of vep20 expressed as a fold induction in CECT4999 cultured in CM9, CM9-E (CM9 + $100 \mu \mathrm{M}$ EDDHA), CM9-Tf (CM9 + $40 \mu \mathrm{M}$ human apo-Tf), CM9-EP [CM9 + fresh eel plasma at a ratio of 1:1 (v/v)], CM9-EP-20/200 (CM9-EP + 20 or $\left.200 \mu \mathrm{M} \mathrm{FeCl}_{3}\right), \mathrm{CM} 9-\mathrm{Hb}(\mathrm{CM} 9+10 \mu \mathrm{M}$ bovine $\mathrm{Hb})$,

CM9-Hb-EDDHA (CM9-Hb + $100 \mu \mathrm{M}$ EDDHA), CM9-EE (CM9 + 1\% eel erythrocytes in PBS + $100 \mu \mathrm{M}$ EDDHA), CM9-HP [CM9 + fresh human plasma at a ratio of $1: 1(\mathrm{v} / \mathrm{v})]$ and CM9-HP-20/200 (CM9-HP +20 or $200 \mu \mathrm{M} \mathrm{FeCl})_{3}$.

B. In vivo transcript/RNA levels of vep20 estimated using qRT-PCR. The eels were bath infected with the wild-type strain (CECT4999) at a dose of $10^{6} \mathrm{cfu} \mathrm{ml}^{-1}$ for $1 \mathrm{~h}$, and the transcript/RNA levels of vep20 were determined in external (gills) and internal (blood, liver, head kidney and spleen) organs at 0, 9, 24 and $72 \mathrm{~h}$ post-challenge using QRT-PCR. The asterisks indicate significantly increased vep20 expression with respect to the vep20 expression levels in bacteria cultured in $\mathrm{CM} 9(P<0.05)$. 


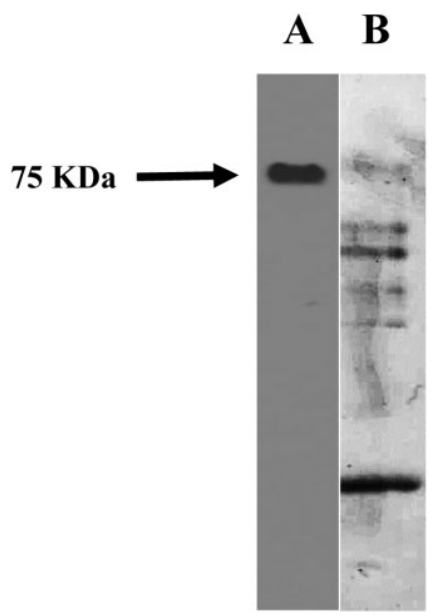

Fig. 5. SDS-PAGE/Western blot analysis of the Vep20-ligand interaction.

A. Western blot detection of the Vep20-ligand complex using Vep20-specific antibodies.

B. SDS-PAGE of albumin-depleted eel plasma; the arrow indicates the molecular weight of the Vep20 ligand.

stationary phase and declining thereafter to nearly undetectable levels in $24 \mathrm{~h}$. Interestingly, both vep20 transcription in CM9-EP versus CM9+apoTf curves were similar, while growth curves were not: the curve for bacteria grown in CM9 media supplemented with human apo-Tf showed a lag phase of more than $4 \mathrm{~h}$, and this effect was not observed for bacteria grown in CM9-EP (Supporting Information Fig. S3).

The transcript/RNA levels of vep20 in samples of internal and external organs from bath-infected eels are shown in Fig. 4B. The expression of vep20 was not upregulated in the gills at any of the assayed times, although the bacterial counts in this organ were the highest observed. In contrast, vep20 expression was notably upregulated in some internal organs, but only during the first $24 \mathrm{~h}$ post-infection. Thus, vep20 was induced at 9 and/or $24 \mathrm{~h}$ post-infection in the blood, liver and spleen and returned to undetectable levels at $72 \mathrm{~h}$ post-infection (Fig. 4B). As expected, the expression levels were associated with bacterial counts in each internal organ (Figs 2 and 4B). These results suggest that Vep20 is a host-specific virulence factor expressed in the internal organs of infected eels during the first $24 \mathrm{~h}$ of infection, consistent with the results obtained in vitro.

\section{Vep20 is a specific receptor for eel transferrin}

vep20 was annotated as a putative $\mathrm{Tf} / \mathrm{Hb} / \mathrm{Hm}$-binding protein. To determine whether vep20 was involved in iron acquisition from $\mathrm{Hb}$, the strains were cultured with commercial $\mathrm{Hm}$ as the sole iron source. No significant differences in growth were observed among wild type, cvep20 and $\Delta v e p 20$ strains, while the minimal $\mathrm{Hm}$ stimulatory concentration was higher than $10 \mu \mathrm{M}$ for the negative control strain, $\triangle$ hupA $\Delta$ hutR, a mutant strain obtained in a previous study, unable to grow using $\mathrm{Hm}$ as the sole iron source (Pajuelo et al., 2014) (Table 1).

To identify the ligand for Vep20, eel plasma proteins were separated using SDS-PAGE and subsequently transferred to a polyvinylidene difluoride (PVDF) membrane, followed by blocking and incubation with an rVep20 protein solution as described in the Materials and methods. The ligand-Vep20 complex was identified using specific-rVep20 antibodies, and the corresponding band (of $74 \mathrm{KDa}$, Fig. 5) was excised and analysed by liquid chromatography coupled with tandem mass spectrometry (LC-MS/MS). The Vep20 ligand was identified as a Tf since the obtained peptides matched proteins corresponding to Tfs from different fish species [Oreochromis niloticus (Nile tilapia), Latimeria chalumnae (West Indian Ocean coelacanth) and Ictalurus punctatus (channel catfish)] (Supporting Information Table S2). Then, we analysed the phylogenetic distance of the eel-Tf from the fish Tfs identified through the proteomic analysis (only Tf from Ictalurus punctatus is included in GenBank). The phylogenetic reconstruction from a common region of 892 positions present in all fish Tfs $(75.1 \%$ pairwise identity, with $26 \%$ of identical sites) showed that spotted gar (Lepisosteus oculatus)-Tf, a fossil marine animal, followed by catfish-Tf and several salmonid-Tfs, including trout-Tf (from Oncorhynchus mykiss), were the closest phylogenetic neighbours to eel-Tf (Fig. 6).

Finally, to confirm that Vep20 is a fish-specific receptor, the strains were cultured with iron-saturated human holotransferrin (holo-Tf) as the sole iron source. Similarly, unlike the negative control $(\Delta v u u A)$, the wild type, cvep20 and $\Delta v e p 20$ strains showed growth with human holo-Tf, and no significant differences were observed among these strains (Table 1).

vep20 is highly conserved within $\mathrm{V}$. vulnificus

vep20 and its putative Furbox were screened through polymerase chain reaction (PCR) in a collection of Bt1, Bt2 and Bt3 strains (Table 2) using the primers listed in Supporting Information Table S1. No amplification product for vep20 was obtained from DNA isolated from Bt1 and Bt3 isolates. In contrast, the DNA samples from all Bt2 strains showed amplification products of the predicted sizes for both Furbox and vep20. These amplification products were sequenced and compared. The analysis showed two types of vep20 proteins (type I and II), differing in one amino acid (proline or histidine), resulting from a single base substitution; notably, type II proteins were present in $62 \%$ of the studied isolates (in Supporting Information Fig. S4). 


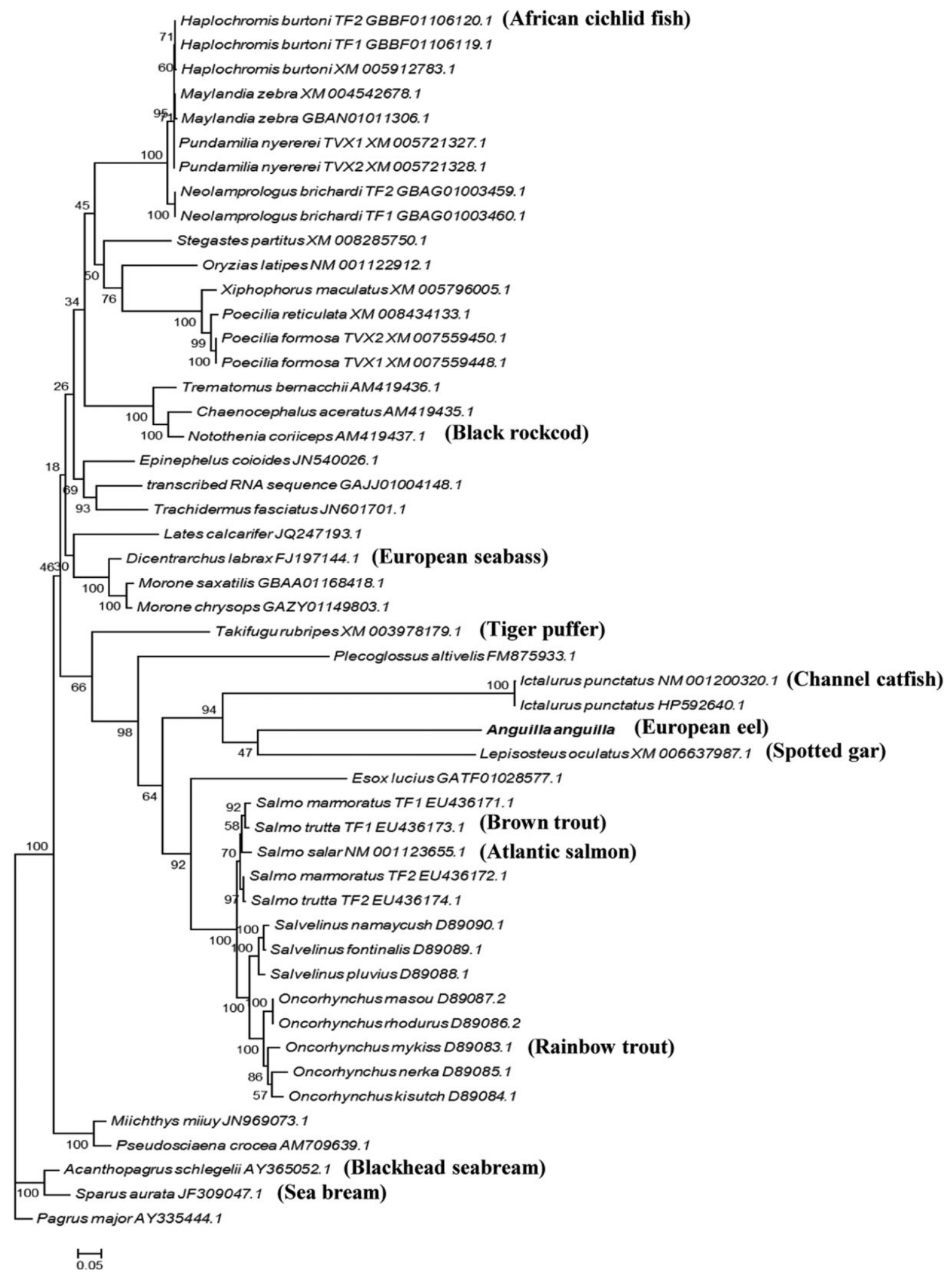

Fig. 6. Molecular phylogenetic analysis of a fish Tf mRNA fragment using the maximum likelihood method based on the general time-reversible model with gamma distribution and evolutionarily invariable sites. Bootstrap support values are indicated in the corresponding nodes as percentages. The tree is drawn to scale, with branch lengths measured as the number of substitutions per site. 
Table 2. Strains and plasmids used in this study.

\begin{tabular}{|c|c|c|}
\hline Designation & Description & Isolation source/reference \\
\hline \multicolumn{3}{|l|}{ V. vulnificus } \\
\hline YJ016 & Biotype 1 & Human blood (Taiwan) \\
\hline MO24-06 & Biotype 1 & Human diseased (South Korea) \\
\hline CMCP6 & Biotype 1 & Human diseased (South Korea) \\
\hline $960426-1 / 4 C$ & Possible biotype 2 serovar $\mathrm{E}$ & Diseased eel (Denmark) \\
\hline CECT4866 & Biotype 2 serovar $\mathrm{E}$ & Human blood (Australia) \\
\hline CIP8190 & Biotype 2 serovar $\mathrm{E}$ & Human blood (France) \\
\hline $94-8-112$ & Biotype 2 serovar $\mathrm{E}$ & Human wound (Denmark) \\
\hline CECT5763 & Biotype 2 serovar $\mathrm{E}$ & Eel tank water (Spain) \\
\hline PD-2-51 & Biotype 2 serovar $\mathrm{E}$ & Eel tank water (Spain) \\
\hline СECT4604 & Biotype 2 serovar $\mathrm{E}$ & Diseased eel (Spain) \\
\hline CECT4602 & Biotype 2 serovar $\mathrm{E}$ & Diseased eel (Spain) \\
\hline CECT4999 & Biotype 2 serovar E & Diseased eel (Spain) \\
\hline CECT4865 & Biotype 2 serovar $\mathrm{E}$ & Diseased shrimp (Taiwan) \\
\hline СЕСТ898 & Biotype 2 serovar $\mathrm{E}$ & Diseased eel (Japan) \\
\hline Rae3 & Biotype 2 serovar $\mathrm{E}$ & Diseased sea bass (Spain) \\
\hline CECT5198 & Biotype 2 serovar A & Diseased eel (Spain) \\
\hline СЕСТ5769 & Biotype 2 serovar A & Diseased eel (Spain) \\
\hline A11 & Biotype 2 serovar A & Diseased eel (Spain) \\
\hline A14 & Biotype 2 serovar A & Diseased eel (Spain) \\
\hline СЕСТ7030 & Biotype 2 serovar A & Diseased eel (Denmark) \\
\hline $95-8-7$ & Biotype 2 serovar I & Diseased eel (Denmark) \\
\hline $95-8-6$ & Biotype 2 serovar I & Diseased eel (Denmark) \\
\hline $95-8-161$ & Biotype 2 serovar I & Diseased eel (Denmark) \\
\hline $95-8-162$ & Biotype 2 serovar I & Diseased eel (Denmark) \\
\hline 11028 & Biotype 3 & Human blood (Israel) \\
\hline$\Delta$ vep20 & CECT4999 vep20-defective mutant & This study \\
\hline$\Delta v u u A$ & CECT4999 vuuA-defective mutant & Pajuelo et al. (2014) \\
\hline$\Delta h u p A \Delta v u u A$ & CECT4999 hupA/vuuA-defective mutant & Pajuelo et al. (2014) \\
\hline$\Delta$ hupA $\Delta$ hutR & CECT4999 hupA/hutR-defective mutant & Pajuelo et al. (2014) \\
\hline$\Delta v e p 20 \Delta h u p A \Delta v u u A$ & CECT4999 vep20/hupA/vuuA-defective mutant & This study \\
\hline cvep20 & $\Delta$ vep20 complemented strain & This study \\
\hline \multicolumn{3}{|l|}{ Other species } \\
\hline Vibrio harveyi & Strain Vib645 & Diseased eel (Tunisia) \\
\hline $\begin{array}{l}\text { Photobacterium damselae } \\
\text { subsp. damselae }\end{array}$ & Strain CECT5064 & Diseased turbot (Spain) \\
\hline E. coli & Strain $\mathrm{DH} 5 \alpha$; cloning strain & Invitrogen \\
\hline E. coli & 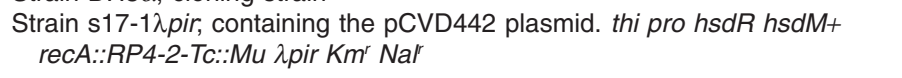 & Simon and colleagues (1983) \\
\hline \multicolumn{3}{|l|}{ Plasmids } \\
\hline pUC18 & Cloning vector $\mathrm{Amp}^{r}$ & Fermentas \\
\hline pCVD442 & Suicide vector; $s a c B$, bla, mobRP4 and R6k ori & Donnenberg and Kaper (1991) \\
\hline plT009 & $\begin{array}{l}\text { Derivative of pJRD215 with the } \mathrm{Sm}^{\mathrm{r}} \text { gene between two } \mathrm{Xmnl} \text { sites replaced } \\
\text { by the multiple-cloning-site containing lac } Z \text { gene cloned from pUC19 }\end{array}$ & Lee et al. (2008) \\
\hline $\mathrm{p} \Delta \mathrm{vep20}$ & pCVD442 with $\Delta v e p 20$ in the MCS & This study \\
\hline pITvep20 & pIT009 with vep20 gene/promoter in the MCS & This study \\
\hline
\end{tabular}

The amino acid sequence alignment of Vep20 with TbpA of Neisseria meningitidis (3V8XA) showed $32 \%$ sequence identity and $74 \%$ query coverage. The 3D structures of both Vep20 types (I and II) are shown in Fig. 7. The best model for Vep20-type I presented $92.6 \%$ of residues (684 aa) in favoured regions, 5.0\% (37 aa) in allowed regions and 3\% (22 aa) in outlier regions while the best for Vep20-type II showed $92.4 \%$ of residues (683 aa) in favoured regions, 4.6\% (34 aa) in allowed regions and $3 \%$ (22 aa) in outlier regions. Both models also showed the best scores for discrete optimized protein energy calculated using Modeller software. vep20 is present in other plasmids from other bacterial fish pathogens

Interestingly, a vep20 homologue with 99.8-99.9\% identity has been identified in the plasmids of two species of fish pathogens, namely $V$. harveyi (pVh1, locus HM752267; http://www.straininfo.net/strains/279230) and $P$. damselae subsp. damselae (formerly V. damselae; pPHDD1, orf150; Rivas et al., 2011). The phylogenetic tree showing the relationships among the three genes and the intraspecific variability in vep20 is presented in Supporting Information Fig. S4. In parallel, an analysis of the 


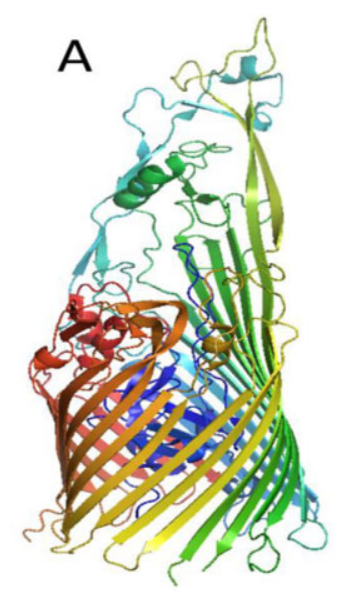

Fig. 7. 3D structure prediction of Vep20. A. Structure of TbpA in Neisseria meningitidis (pdb ID 3 V8XA), the template protein used for modelling.

B. Predicted structure of Vep20 type-I protein. C. Predicted structure of Vep20 type-II protein. In $\mathrm{B}$ and $\mathrm{C}$, the position and the amino acid change in both forms of Vep20 are indicated.

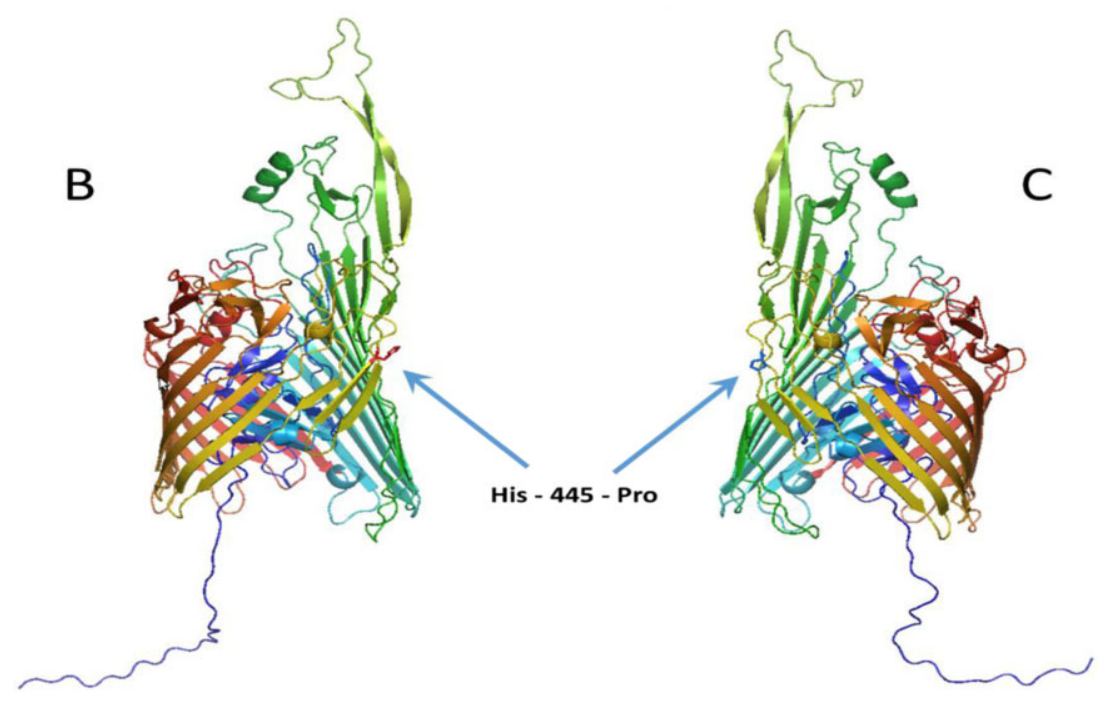

Furbox showed that this sequence was identical in all Vibrio isolates (GATAATGATAATCATTATT), while that of $P$. damselae showed a $79 \%$ sequence identity with respect to the Vibrio isolates (GATAAATATTATCATTATC).

\section{Discussion}

The first human and fish vibriosis cases caused by V. vulnificus were reported in the 1970s. Since then, many studies on the virulence mechanisms involved in human vibriosis have been performed (Gulig et al., 2005; Jones and Oliver, 2009). Most of these studies suggest that all the strains of this species could potentially be pathogenic for humans because all of the analysed virulence genes are present in both clinical and environmental strains (Gulig et al., 2005; Jones and Oliver, 2009). In contrast, studies on the virulence mechanisms involved in fish vibriosis have demonstrated that only Bt2 strains can infect and cause disease in fish, eventually leading to death from sepsis. This ability relies, in part, on a virulence plasmid ( $p$ vvbt2) whose elimination leads to the loss of resistance to eel innate immunity and concomitantly, virulence for eels (Lee et al., 2008; Valiente et al., 2008). The plasmid pVvbt2 is approximately $69 \mathrm{~Kb}$ in size and contains a cluster of genes, duplicated in chromosome II, for the synthesis and transport of a new variant of MARTX toxin (multifunctional autoprocessive repeat in toxin) involved in resistance to phagocytosis and fish death (Lee et al., 2013). The plasmid also contains a gene, vep20, identified in a previous study as putatively regulated by Fur (Pajuelo et al., 2014). In this context, could vep20 also confer resistance to eel innate immunity?

To test it, we constructed a vep20 mutant and a triple mutant that had inactivated the two described iron-uptake mechanisms as well as vep20. As expected, the virulence for mice as well as the ability to resist and grow in human plasma was not altered by deleting vep20 while the virulence for eels together with the ability to grow in eel blood and plasma were notably impaired in $\Delta v e p 20$. Then, we 
found that vep20 expression was induced by iron restriction, regardless of the chemical nature of the iron-chelator added to the medium, and that a minimum percentage of eel plasma is needed to establish the iron-restricted conditions for gene induction. In addition, vep20 was overexpressed in vitro at the beginning of the log phase and ended just before the stationary phase of growth, suggesting the involvement of vep20 in active growth. The same results were obtained by Pajuelo et al. (2014) for hupA and vuuA, indicating that these three genes are involved in response to iron starvation.

On the basis of the results obtained, we hypothesized that Vep20 was involved in growth in eel blood and internal organs in vivo. To demonstrate it, we performed an in vivo colonization and invasion assay with waterborneinfected eels. We found that the mutant was unable to efficiently colonize the internal organs of eels. This finding correlates with the results found in vitro and explains the severe impairment of $\Delta$ vep20 in virulence for eels. In parallel, we demonstrated that vep20 was over-expressed in vivo by the wild-type strain but only in blood and internal organs for the first $24 \mathrm{~h}$ of infection, time that this pathogen needs for a successful invasion to result in systemic infection (Lee et al., 2013).

The overall results demonstrate that vep20 is a hostspecific virulence gene that encodes Vep20, an IROMP of approximately $80 \mathrm{kDa}$, which facilitates bacterial multiplication in eel blood through the binding of a blood protein that serves as an iron source for the bacterium. Eel-Tf is the most likely ligand for the Vep20, as the only proteins that showed positive matches in the proteomic database were the Tf proteins from catfish, coelacanth (L. chalumnae), a living fossil species belonging to the oldest known living lineage of Sarcopterygii (lobe-finned fish and tetrapods), and Nile tilapia, one of the most evolved teleosts, described as a potential host for V. vulnificus (Fouz et al., 2000). Additionally, the phylogenetic analysis using a common fragment present in 50 fish-Tf genes was consistent with the results obtained through LC-MS/MS, showing that eel-Tf is also closely related with trout-Tf, another fish species that hosts V. vulnificus (Pederssen et al., 2008). These findings support the hypothesis that Vep20 also binds Tf proteins from tilapia and trout, although with less efficiency, revealing the lower virulence of $V$. vulnificus for these two species $\left(\mathrm{LD}_{50}\right.$ approximately $2-3 \log$ units higher than that for eel) (Fouz et al., 2000; 2010).

In parallel, we observed that the identity of vep20 and its Furbox in the different clonal complexes of the Bt2 was nearly $100 \%$. The high conservation of Vep20 within Bt2 could reflect the recent acquisition of the virulence plasmid or the strong selective pressure for the vep20 gene. Surprisingly, a gene with nearly $100 \%$ homology to vep20 is present in an uncharacterized virulence plasmid of $V$. harveyi ( $\mathrm{pVh} 1$ ) and another gene (orf150) with $76 \%$ identity to vep20 is also present in a virulence plasmid of the zoonotic pathogen $P$. damselae subsp damselae (formerly V. damselae). Vibrio harveyi causes diseases in gilthead sea bream, sea bass, common snook (Centropomus undecimalis), horse mackerel (Trachurus japonicus), milkfish (Chanos chanos), red drum (Sciaenops ocellatus), sharks (Carcharhinus plumbeus, Negaprion breviorstris), sole (Solea senegalensis), summer flounder (Paralichthys dentatus) and tiger puffer (Takifugu rubripes; Austin and Austin, 2012), while P. damselae causes septicaemia in damselfish, eel (Anguilla anguilla), brown shark (Carcharhinus plumbeus), yellowtail (Seriola quinqueradiata), seabreams (Sparus spp.) and turbot (Scophthalmus spp.) as well as wound infections in humans similar to those induced through V. vulnificus (Austin and Austin, 2012). Interestingly, the plasmid of $P$. damselae is transferable via conjugation (Rivas et al., 2011), and the plasmid of $V$. harveyi, although still uncharacterized, contains a set of tra genes (http://www.straininfo.net/strains/279230). These data suggest that Vep20 could represent a new family of plasmid-encoded Tf-binding receptors specific for fish and transferable through horizontal gene transfer, conferring an adaptive advantage to transconjugants in fish-farming environments. The differences in Vep20 amino acid sequences among strains could reflect changes resulting from host adaptation. Indeed, approximately $13 \%$ of the Tf sequences in salmonids undergo positive selection through competition with bacterial pathogens for iron (Ford, 2001). Similarly, pathogens could change amino acids through mutations that facilitate the adaptation of these bacteria to changes in the hosts.

In conclusion, vep20 is a host-specific virulence factor specifically involved in iron acquisition from fish-Tf. This novel iron acquisition system is complemented by two other host-non-specific systems also involved in the virulence of $V$. vulnificus not only in the eel but also in humans. The existence of this third system emphasizes the importance of iron in $V$. vulnificus-mediated sepsis and explains, at least partially, why $V$. vulnificus presents much higher virulence for eels $\left(L_{50}\right.$ approximately $10^{1-2} \mathrm{cfu}$ per $\mathrm{g}$ of fish) than for mice $\left(\mathrm{LD}_{50}\right.$ approximately $10^{4-6}$ per gram of mouse), unless the blood iron load is high ( $\mathrm{LD}_{50}$ approximately $10^{1-2} \mathrm{cfu}$ per $\mathrm{g}$ of mouse in an iron-overloaded model). Moreover, Vep20 could represent a new protein family encoded in transferable plasmids specific for fish pathogens, namely Ftbp (fish transferrin binding proteins). The acquisition of these plasmids in aquatic bacteria might contribute to the fitness of the transconjugant by increasing the host range and, therefore, the persistence of the strain (or clone) in fish-farming environments. 


\section{Experimental procedures}

\section{Bacterial strains and growth conditions}

The bacterial strains used in the study are listed in Table 2. The bacteria were routinely grown in LB-1/LBA-1 (LuriaBertani broth/agar, $1 \% \mathrm{NaCl}$ ) or $\mathrm{CM} 9 / \mathrm{CM} 9 \mathrm{~A}$ [M9 minimal medium broth/agar (Miller, 1972) supplemented with $0.2 \%$ casamino acids (Difco)] at $28^{\circ} \mathrm{C}$ (V. vulnificus) or $37^{\circ} \mathrm{C}$ (Escherichia coli) and stored in LB-1 plus glycerol (17\%) at $-80^{\circ} \mathrm{C}$. When necessary, ampicillin $\left(100 \mu \mathrm{g} \mathrm{ml}^{-1}\right)$ or polymyxin $\mathrm{B}\left(50 \mathrm{U} \mathrm{ml}^{-1}\right)$ was added to the media. For growth experiments under different iron-starvation conditions, fresh blood, plasma and erythrocytes from eels and plasma from humans were obtained as previously described (Amaro et al., 1994; Esteve-Gassent et al., 2004; human plasma was obtained from Sigma). The bacteria were grown in CM9-HP [CM9 + fresh human plasma at a ratio of 1:1 (v/v)], CM9-EP [CM9 + eel plasma at a ratio of 1:1 (v/v)], CM9-HP-20/200 $\left(\mathrm{CM} 9-\mathrm{HP}+20\right.$ or $200 \mu \mathrm{M} \mathrm{FeCl}{ }_{3}$ ), CM9-EP-20/200 (CM9$\mathrm{EP}+20$ or $\left.200 \mu \mathrm{M} \quad \mathrm{FeCl}_{3}\right), \mathrm{CM} 9-\mathrm{EE} \quad[\mathrm{CM} 9+1 \%$ eel erythrocytes in PBS $+100 \mu \mathrm{M}$ ethylenediamine-di-(ohydroxyphenylacetic acid) (EDDHA; Sigma)], CM9-Fe $\left.(\mathrm{CM} 9+100 \mu \mathrm{M} \mathrm{FeCl})_{3}\right), \mathrm{CM} 9-\mathrm{Hb}[\mathrm{CM} 9+10 \mu \mathrm{M}$ bovine $\mathrm{Hb}$ (Sigma)], CM9-Hb-EDDHA (CM9-Hb + $100 \mu \mathrm{M}$ EDDHA), CM9-Tf $[40 \mu \mathrm{M}$ iron-free human apo-transferrin (apo-Tf; Sigma)], CM9-E (100 $\mu \mathrm{M}$ EDDHA) and CM9A-E (CM9 agar + $100 \mu \mathrm{M}$ EDDHA) according to Pajuelo et al. (2014).

\section{Animal maintenance}

Both mice (6- to 8-week-old BALB/c mice purchased in Harlan Laboratory Models S.L.) and eels (farmed European eel Anguilla anguilla, purchased from a local eel farm that does not vaccinate against $V$. vulnificus) were maintained, prepared and handled as previously described (Pajuelo et al., 2014). Three populations of 10,20 and $100 \mathrm{~g}$ were used for virulence assays, colonization assays and blood extraction respectively. All animal experiment protocols were reviewed and approved through the Animal Ethics Committee of National Cheng Kung University and the University of Valencia.

\section{DNA and RNA manipulations}

Genomic DNA was extracted from overnight cultures in CM9 according to Ausubel and colleagues (2007), and total RNA was extracted from tissues or mid-log phase cultures in CM9 [inoculated from overnight cultures in CM9 at a ratio of $1: 1$ $(\mathrm{v} / \mathrm{v})$ ] using TRI reagent (Sigma) according to the manufacturer's instructions. The RNA was subjected to DNase treatment using TURBO ${ }^{\mathrm{TM}}$ DNase (Ambion) to digest and eliminate residual DNA, according to the manufacturer's instructions. The RNA was cleaned using the Rneasy ${ }^{\circledR}$ MinEute ${ }^{\circledR}$ Cleanup Kit (Qiagen) according to the manufacturer's instructions and quantified using a Nanodrop ND-2000. Only samples with $A_{260} / A_{280}>1.8$ and $A_{260} / A_{230}>2$ were selected.

\section{$P C R$, sequencing and quantitative reverse transcription ( $q R T)-P C R$}

The DNA fragments were amplified, visualized and sequenced in several of the strains shown in Table 2 accord- ing to Pajuelo et al. (2014). To quantify the gene expression, qRT-PCR was performed according to Pajuelo et al. (2014). The housekeeping gene $\operatorname{rec} A$ was used as a standard, and the fold induction $\left(2^{-\Delta \Delta \mathrm{Ct}}\right)$ for vep20 gene was calculated according to Livak and Schmittgen (2001). The primers for vep20 and the putative Furbox were designed from based on the virulence plasmid sequence of strain CECT4999 (AM293858; Supporting Information Table S1).

\section{Isolation of mutant and complemented strains}

A single in-frame deletion mutant in the vep20 gene was obtained through allelic exchange (Shao and Hor, 2000). Briefly, the regions up- and down-stream of vep20 were cloned into pCVD442, a suicide vector for negative section using sucrose (Donnenberg and Kaper, 1991), to generate $\mathrm{p} \Delta$ vep20, containing an in-frame deletion of a major portion of the coding sequence (Table 2). The plasmid $\mathrm{p} \Delta$ vep20 was

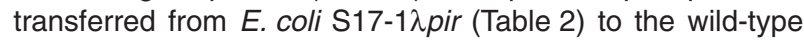
strain CECT4999 via conjugation. The transconjugants were selected using ampicillin and polymyxin B and subsequently screened for colonies that lost pCVD442 via a second homologous recombination event based on resistance to LB supplemented with $10 \%$ sucrose. To obtain the vep20, hupA and vuuA triple mutant, $\mathrm{p} \Delta v e p 20$ was transferred via conjugation into the $\triangle$ hupA $\Delta$ vuuA double mutant strain (Table 2), and a second recombination was performed as described above. In trans complementation was performed through the conjugal transfer of pITvep20 (Table 2). Plasmid pITvep20 was generated after cloning the coding sequence and promoter region of vep20, obtained through PCR amplification with primers vep20-cF/vep20-cR (Supporting Information Table S1), into plT009 (Table 2; Lee et al., 2008).

In vitro phenotypic characterization of $\Delta \mathrm{vep} 20$.

- OMP analysis. Wild type and $\Delta$ vep20 strains were grown in CM9-Fe and CM9-Tf for $6 \mathrm{~h}$, and subsequently OMP was extracted as previously described (Biosca et al., 1993). Outer membrane protein samples were fractionated using SDSPAGE (Laemmli, 1970) with a 10\% acrylamide separation gel. The protein bands were stained with Coomassie brilliant blue.

- Bioassays. To determine the ability of wild type and $\Delta v e p 20$ strains to use iron from iron-saturated human holotransferrin [holo-Tf (Sigma)], we measured the growth halo around discs soaked in a $1 \mathrm{mM}$ solution on CM9A-E plates previously inoculated with $100 \mu \mathrm{l}$ of an overnight culture in CM9 (Simpson and Oliver, 1987). To determine the minimal stimulatory concentration (MSC) of bovine $\mathrm{Hm}$ (Sigma) CM9 medium supplemented with $100 \mu \mathrm{M}$ EDDHA was inoculated with several different concentrations of $\mathrm{Hm}$ (from 0.1 to $10 \mu \mathrm{M})$ from overnight cultures [ratio 1:1 (v/v)]; the MSC of bovine $\mathrm{Hm}$ was determined as the minimum concentration required for bacterial growth. The mutants defective in vuuA and hupA/hutR (Pajuelo et al., 2014) were used as negative controls for growth on human holo-Tf or in $\mathrm{Hm}$ assays respectively.

- Growth in plasma and blood. A $100 \mu$ l aliquot of bacterial suspension in PBS containing $10^{3} \mathrm{cfu} \mathrm{ml}^{-1}$ grown overnight in 
CM9 was added to $100 \mu \mathrm{l}$ of fresh plasma or blood, and the mixtures were incubated at $28^{\circ} \mathrm{C}$ (for eel plasma) or $37^{\circ} \mathrm{C}$ (for human plasma) for $4 \mathrm{~h}$ with shaking (160 r.p.m.). Samples were collected at 0 and $4 \mathrm{~h}$ post-incubation, and the viable bacteria were enumerated using the drop plate method (Hoben and Somasegaran, 1982). The bactericidal (complement) or bacteriostatic ( $\mathrm{Tf}$ ) activity of plasma was abolished after heating at $56^{\circ} \mathrm{C}$ for $30 \mathrm{~min}$ (Amaro et al., 1997) or supplementing with $100 \mu \mathrm{M}$ of $\mathrm{FeCl}_{3}$ respectively.

- Interaction with eel blood cells. Granulocytes and erythrocytes were obtained from eel blood according to Lee and colleagues (2013). Eukaryotic cells were seeded onto polyL-lysine treated 96-well plates (NUNC) at a concentration of $10^{5}$ cells per well, and bacterial strains grown overnight in CM9 were added at a multiplicity of infection (moi) of 10 . Phagocytic activity and survival inside the phagocytes were analysed, and haemolysis was microscopically observed according to Lee and colleagues (2013).

In vivo phenotypic characterization of $\Delta \mathrm{vep} 20$.

- Virulence. The bacterial virulence for European elvers of $10 \mathrm{~g}$ in 6- to 8-week-old BALB/c mice, expressed as the LD $_{50}$ (lethal dose to $50 \%$ of animal), was determined as previously described (Amaro et al., 1994; 1995). The LD $_{50}$ was calculated as previously described (Reed and Münch, 1938) and expressed as cfu $\mathrm{g}^{-1}$ (i.p. injection) or $\mathrm{ml}$ of infectious bath (immersion challenge).

- Colonization. The eels were bath infected with the wild type or mutant strain grown overnight in LB-1 at a dose equivalent to the $\mathrm{LD}_{50}$ of the wild-type strain (Amaro et al., 1995). A total of 24 eels per strain were infected, and six eels were immersed under the same conditions in PBS-1. Twelve live eels were randomly sampled at $0,9,24$ and $72 \mathrm{~h}$, at a ratio of three animals per sampling time (Pajuelo et al., 2014). The bacterial number per $\mathrm{ml}$ (blood) or $\mathrm{g}$ (gills, liver, kidney and spleen) of sample was estimated using the drop plate method.

\section{Analysis of Vep20.}

- Bioinformatics analysis. The online programmes PsortB (Yu et al., 2010) for cellular location, SecretomeP (Dyrløv-Bendtsen et al., 2005) for peptide secretion signals and pFam (Punta et al., 2012) for functional domains were used. The Vep20 amino acid sequences in $V$. vulnificus strains CECT4999 and CECT4602 (741 aa) were used to generate the $3 \mathrm{D}$ structure model of Vep20 protein. To identify the templates for modelling, a BLASTP search was performed against the Protein Data Bank (pdb). Modeller 9.13 software (academic version; Sali and Blundell, 1993) was used to predict the structure based on the selected template (ID pdb 3 V8X chain A; Noinaj et al., 2012). For each protein, five models were generated, and one model was selected based on the Ramachandran plot (Lovell et al., 2002) obtained using the online server Rampage (http:// mordred.bioc.cam.ac.uk/ rapper/rampage.php).

- Purification of rVep20 and polyclonal antibodies. The entire vep20 nucleotide sequence was PCR amplified using the primers rVep20-F/R (Supporting Information Table S1). The amplicons were cloned into vector pQE-30 (Qiagen), transformed in the expression strain E. coli M15 and $\mathrm{His}_{6}{ }^{-}$ tagged-Vep20 (rVep20) recombinant protein was induced using Isopropyl $\beta$-D-1-thiogalactopyranoside (IPTG), followed by purification using a nickel affinity column (NiNTA) according to the manufacturer's instructions (Qiagen). Polyclonal antibodies against rVep20 were obtained after the i.p. immunization of 8-week-old specific pathogen-free BALB/c female mice (Antibody BCN, Spain) with $50 \mu \mathrm{g}$ of pure antigen combined 1:1 (v/v) with complete Freund's adjuvant. The remaining doses contained $50 \mu \mathrm{g}$ of pure antigen combined with incomplete Freund's adjuvant in five doses every 15 days. A week after the last immunization, the blood samples were pooled and used as polyclonal antibodies against rVep20. Blood samples from non-immunized mice were obtained and used as a control.

- Western blot. For each tested condition, the bacteria were grown overnight in $\mathrm{CM} 9$, diluted 1:100 (v/v) in fresh medium and sampled at $6 \mathrm{~h}$ or the indicated times (for CM9-EP). A sample of $5 \mu \mathrm{g}$ of protein, quantified using the Pierce BCA Protein Assay Kit (Thermo Scientific), was separated through SDS-PAGE (Laemmli, 1970) on discontinuous gels $(4 \%$ stacking gel, $10 \%$ separating gel). The proteins were transferred onto a PVDF membrane $(0.2 \mu \mathrm{m}$, Bio-Rad) at $100 \mathrm{~V}$ for $1 \mathrm{~h}$ in Tris-glycine-methanol transfer buffer [25 mM Tris, $192 \mathrm{mM}$ glycine ( $\mathrm{pH} \mathrm{8.3),} \mathrm{20 \%} \mathrm{(vol/vol)} \mathrm{methanol]} \mathrm{according}$ to Towbin and colleagues (1979). The membranes were blocked with $5 \%$ non-fat dry milk, and immunostaining was performed using a mouse Vep20-specific primary antibody diluted 1:3000 and anti-mouse IgG HRP-conjugated secondary antibody diluted 1:5000 (Sigma). The proteins were visualized using Immobilon Western Chemiluminescent HRP Substrate (Millipore) on a Curix 60 Revelator (AGFA Healthcare).

- Vep20 ligand identification through LC-MS/MS analysis. To avoid interferences in the binding-assay, albumin was depleted from fresh eel plasma according to Chen and colleagues (2005). The plasma proteins were separated using SDS-PAGE and subsequently transferred to a PVDF membrane as described above. The membrane was blocked with $5 \%$ non-fat dry milk and incubated with $5 \mu \mathrm{g}$ of rVep20 in blocking solution for $90 \mathrm{~min}$ at room temperature to facilitate rVep20-ligand binding. Specific-Vep20 polyclonal antibodies were used to reveal the band corresponding to the Vep20ligand complex. The bands in the eel plasma SDS-PAGE corresponding to the Western blot signals were excised, digested with sequencing grade trypsin (Promega) as described elsewhere (Shevchenko et al., 1996) and identified through LC-MS/MS according to Pamblanco et al. (2014).

\section{Phylogenetic reconstruction for vep20, vep20 homologues and the fish transferrin gene}

Phylogenetic trees were reconstructed using the maximum likelihood method. Support for the groupings derived in these reconstructions was evaluated through bootstrapping using 1000 replicates (Felsenstein, 1985). Maximum likelihood 
trees were obtained using PhyML (Guindon and Gascuel, 2003). The best evolutionary model for the sequences according to jModelTest (Posada, 2008) and considering the Akaike information criterion was the general time-reversible model of substitution with a gamma distribution (GTR+G; Nei and Kumar, 2000) for the analysis of the Tf mRNA and Tamura Nei model (TN93; Tamura and Nei, 1993) for vep20 and its homologues. These models were used to obtain the maximum likelihood trees presented in this study. An 854-nt fragment of $A$. anguilla Tf mRNA (Supporting Information Appendix S1) was obtained through Blast searches using SRA collections (SRR931776-SRR931780) as query for the Tf gene of Salmo salar (NM_001123655.1) and subject sequences for the different SRA files. The remaining Tf sequences were obtained through Blast searches among the fish species included in these analyses with higher than $60 \%$ identity to the Tf of Anguilla anguilla. The vep20 sequences in V. vulnificus strains CECT4999 (AM293858.1, locus VVULR99_30) and CECT4602 (AM293860.1, locus vpb35), $V$. harveyi strain Vib645 and Photobacterium damsela strain RM71 were obtained from GenBank (accession numbers indicated in Supporting Information Fig. S4), and the vep20 sequences in Bt2 strains were submitted to GenBank (accession numbers KM100335-KM100349 and KP202344KP202349).

\section{Acknowledgements}

This work was financially supported through grants AGL2011-29639 (co-funded with FEDER funds) and Programa Consolider-Ingenio 2010 CSD2009-00006 from MICINN (Spain) and grant NSC 97-2320-B-006-009-MY3 from the National Science Council (Taiwan). The authors would like to thank the Conselleria de Educación Formación y Ocupación de Valencia por la ayuda Gerónimo Forteza FPA/2011/023. The authors would also like to thank the 'Servei Central de Suport a la Investigació Experimental' of the University of Valencia for technical support for the sequence analyses.

\section{References}

Amaro, C., and Biosca, E.G. (1996) Vibrio vulnificus biotype 2, pathogenic for eels, is also an opportunistic pathogen for humans. Appl Environ Microbiol 62: 1454-1457.

Amaro, C., Biosca, E.G., Fouz, B., Toranzo, A.E., and Garay, E. (1994) Role of iron, capsule, and toxins in the pathogenicity of Vibrio vulnificus biotype 2 for mice. Infect Immun 62: 759-763.

Amaro, C., Biosca, E.G., Fouz, B., Alcaide, E., and Esteve, C. (1995) Evidence that water transmits Vibrio vulnificus biotype 2 infections to eels. Appl Environ Microbiol 61: 1133-1137.

Amaro, C., Fouz, B., Biosca, E.G., Marco-Noales, E., and Collado, R. (1997) The Lipopolysaccharide O side chain of Vibrio vulnificus serovar $\mathrm{E}$ is a virulence determinant for eel. Infect Immun 65: 2475-2479.

Austin, B., and Austin, D.A. (2012) Bacterial Fish Pathogens: Disease of the Farmed and Wild Fish, 5th edn. Dordrecht, the Netherlands: Springer.
Ausubel, F.M., Brent, R., Kingston, R.E., Moore, D.D., Seidman, J.G., Smith, J.A., and Struhl, K. (2007) Current Protocols in Molecular Biology. New York, NY, USA: Wiley Interscience.

Biosca, E.G., Amaro, C., Esteve, C., Alcaide, E., and Garay, E. (1991) First record of Vibrio vulnificus biotype 2 from diseased European eel, Anguilla anguilla. L. J Fish Dis 14: 103-109.

Biosca, E.G., Llorens, H., Garay, E., and Amaro, C. (1993) Presence of a capsule in Vibrio vulnificus biotype 2 and its relationship to virulence for eels. Infect Immun 61: 16111618.

Biosca, E.G., Fouz, B., Alcaide, E., and Amaro, C. (1996) Siderophore-mediated iron acquisition mechanisms in Vibrio vulnificus biotype 2. Appl Environ Microbiol 62: 928935.

Bullen, J.J., Spalding, P.B., Ward, C.G., and Gutteridge, J.M. (1991) Hemochromatosis, iron and septicemia caused by Vibrio vulnificus. Arch Intern Med 151: 1606-1609.

Chen, Y.Y., Lin, S.Y., Yeh, Y.Y., Hsiao, H.H., Wu, C.Y., Chen, S.T., and Wang, A.H. (2005) A modified protein precipitation procedure for efficient removal of albumin from serum. Electrophoresis 26: 2117-2127.

Dechet, A.M., Yu, P.A., Koram, N., and Painter, J. (2008) Nonfoodborne Vibrio infections: an important cause of morbidity and mortality in the United States, 1997-2006. Clin Infect Dis 46: 970-976.

Donnenberg, M.S., and Kaper, J.B. (1991) Construction of an eae deletion mutant of enteropathogenic Escherichia coli by using a positive-selection suicide vector. Infect Immun 59: 4310-4317.

Dyrløv-Bendtsen, J., Kiemer, L., Fausbøll, A., and Brunak, S. (2005) Non-classical protein secretion in bacteria. BMC Microbiol 5: 58.

Esteve-Gassent, M.D., Fouz, B., and Amaro, C. (2004) Efficacy of a bivalent vaccine against eel diseases caused by Vibrio vulnificus after its administration by four different routes. Fish Shellfish Immunol 16: 93-105.

Felsenstein, J. (1985) Confidence limits on phylogenies: an approach using the bootstrap. Evolution 39: 783-791.

Ford, M.J. (2001) Molecular evolution of transferrin: evidence for positive selection in salmonids. Mol Biol Evol 18: 639647.

Fouz, B., Alcaide, E., Barrera, R., and Amaro, C. (2000) Susceptibility of Nile tilapia (Oreochromis niloticus) to vibriosis due to Vibrio vulnificus biotype 2 (serovar E). Acquaculture 212: 21-30.

Fouz, B., Llorens, A., Valiente, E., and Amaro, C. (2010) A comparative epizootiologic study of the two fish-pathogenic serovars of Vibrio vulnificus biotype 2. J Fish Dis 33: 383390.

Guindon, S., and Gascuel, O. (2003) A simple, fast, and accurate algorithm to estimate large phylogenies by maximum likelihood. Syst Biol 52: 696-704.

Gulig, P.A., Bourdage, K.L., and Starks, A.M. (2005) Molecular pathogenesis of Vibrio vulnificus. J Microbiol 43: 118131.

Haenen, O.L., Van Zanten, E., Jansen, R., Roozenburg, I., Engelsma, M.Y., Dijkstra, A., et al. (2014) Vibrio vulnificus outbreaks in Dutch eel farms since 1996: strain diversity and impact. Dis Aquat Organ 108: 201-209. 
Hoben, H.J., and Somasegaran, P. (1982) Comparison of the pour, spread, and drop plate methods for enumeration of Rhizobium spp. in inoculants made from presterilized peat. Appl Environ Microbiol 44: 1246-1247.

Hor, L.I., Gao, C.T., and Wan, L. (1995) Isolation and characterization of Vibrio vulnificus inhabiting the marine environment of the southwestern area of Taiwan. J Biomed Sci 2: 384-389.

Hor, L.I., Chang, Y.K., Chang, C.C., Lei, H.Y., and Ou, J.T. (2000) Mechanism of high susceptibility of iron-overloaded mouse to Vibrio vulnificus infection. Microbiol Immunol 44: 871-878.

Horseman, M.A., and Surani, S. (2011) A comprehensive review of Vibrio vulnificus: an important cause of severe sepsis and skin and soft-tissue infection. Int $J$ Infect Dis 3: 157-166.

Jones, M.K., and Oliver, J.D. (2009) Vibrio vulnificus: disease and pathogenesis. Infect Immun 77: 1723-1733.

Laemmli, U.K. (1970) Cleavage of structural proteins during the assembly of the head of bacteriophage T4. Nature 227: 680-685.

Lee, C.T., Amaro, C., Wu, K.M., Valiente, E., Chang, Y.F., Tsai, S.F., et al. (2008) A common virulence plasmid in biotype 2 Vibrio vulnificus and its dissemination aided by a conjugal plasmid. J Bacteriol 190: 1638-1648.

Lee, C.T., Pajuelo, D., Llorens, A., Chen, Y.H., Leiro, J.M., Padrós, F., et al. (2013) MARTX of Vibrio vulnificus biotype 2 is a virulence and survival factor. Environ Microbiol 15: 419-432.

Litwin, C.M., and Byrne, B.L. (1998) Cloning and characterization of an outer membrane protein of Vibrio vulnificus required for heme utilization: regulation of expression and determination of the gene sequence. Infect Immun 66: 3134-3141.

Livak, K.J., and Schmittgen, T.D. (2001) Analysis of relative gene expression data using real time quantitative PCR and the $2^{-\Delta \Delta \mathrm{Ct}}$ method. Methods 25: 402-408.

Lovell, S.C., Davis, I.W., Arendall, W.B., de Bakker, P.I.W., Word, J.M., Prisant, M.G., et al. (2002) Structure validation by $\mathrm{C}$ alpha geometry: phi, psi and $\mathrm{C}$ beta deviation. Proteins 50: 437-450.

Miller, J.H. (1972) Experiments in Molecular Genetics. Cold Spring Harbor, NY, USA: Cold Spring Harbor Laboratory Press.

Nei, M., and Kumar, S. (2000) Molecular Evolution and Phylogenetics. New York, NY, USA: Oxford University Press.

Noinaj, N., Easley, N.C., Oke, M., Mizuno, N., Gumbart, J., Boura, E., et al. (2012) Structural basis for iron piracy by pathogenic Neisseria. Nature 483: 53-58.

Pajuelo, D., Lee, C.T., Roig, F.J., Lemos, M.L., Hor, L.I., and Amaro, C. (2014) Host-nonspecific iron acquisition systems and virulence in the zoonotic serovar of Vibrio vulnificus. Infect Immun 82: 731-744.

Pamblanco, M., Oliete, P., García, E., Valero, L., Sanchez, M.M., and Rodríguez, S. (2014) Unveiling novel interactions of histone chaperone Asf1 linked to TREX-2 factors Sus1 and Thp1. Nucleus 13: 247-259.

Pederssen, K., Skall, H.F., Lassen-Nielsen, A.M., Nielsen, T.F., Henriksen, N.H., and Olesen, N.J. (2008) Surveillance of health status on eight marine rainbow trout,
Oncorhynchus mykiss (Walbaum), farms in Denmark in 2006. J Fish Dis 31: 659-667.

Pfeffer, C.S., Hite, M.F., and Oliver, J.D. (2003) Ecology of Vibrio vulnificus in estuarine waters of eastern North Carolina. Appl Environ Microbiol 69: 3526-3531.

Posada, D. (2008) jModelTest: phylogenetic model averaging. Mol Biol Evol 25: 1253-1256.

Punta, M., Coggill, P.C., Eberhardt, R.Y., Mistry, J., Tate, J., Boursnell, C., et al. (2012) The Pfam protein families database. Nucleic Acids Res 40 (Database Issue): 290-301.

Reed, M.J., and Münch, M. (1938) A simple method for estimating fifty percent endpoints. Am J Hyg 27: 493-497.

Rivas, A.J., Balado, M., Lemos, M.L., and Osorio, C.R. (2011) The Photobacterium damselae subsp. damselae hemolysins damselysin and HlyA are encoded within a new virulence plasmid. Infect Immun 79: 46174627.

Sali, A., and Blundell, T.L. (1993) Comparative protein modelling by satisfaction of spatial restraints. $J$ Mol Biol 234: 779-815.

Shao, C.P., and Hor, L.I. (2000) Metalloprotease is not essential for Vibrio vulnificus virulence in mice. Infect Immun 68: 3569-3573.

Shevchenko, A., Jensen, O.N., Podtelejnikov, A.V., Sagliocco, F., Wilm, M., Vorm, O., et al. (1996) Linking genome and proteome by mass spectrometry: large-scale identification of yeast proteins from two dimensional gels. Proc Natl Acad Sci U S A 93: 14440-14445.

Simon, R., Priefer, U., and Puhler, A. (1983) A broad host range mobilization system for in vivo genetic-engineering transposon mutagenesis in gram negative bacteria. Biotechnology 1: 787-796.

Simpson, L.M., and Oliver, J.D. (1987) Ability of Vibrio vulnificus to obtain iron from transferrin and other ironbinding proteins. Curr Microbiol 15: 155-157.

Tamura, K., and Nei, M. (1993) Estimation of the number of nucleotide substitutions in the control region of mitochondrial DNA in humans and chimpanzees. Mol Biol Evol 10: 512-526.

Towbin, H., Staehelin, T., and Gordon, T. (1979) Electrophoretic transfer of proteins from polyacrylamide gels to nitrocellulose sheets: procedure and some applications. Proc Natl Acad Sci. 76: 4350-4354.

Valiente, E., Lee, C.T., Hor, L.I., Fouz, B., and Amaro, C. (2008) Role of the metalloprotease Vvp and the virulence plasmid pR99 of Vibrio vulnificus serovar $E$ in surface colonization and fish virulence. Environ Microbiol 10: 328-338.

Yu, N.Y., Wagner, J.R., Laird, M.R., Melli, G., Rey, S., Lo, R., et al. (2010) PSORTb 3.0: Improved protein subcellular localization prediction with refined localization subcategories and predictive capabilities for all prokaryotes. Bioinformatics 26: 1608-1615.

\section{Supporting information}

Additional Supporting Information may be found in the online version of this article at the publisher's web-site:

Fig. S1. Interaction of V. vulnificus strains with eel granulocytes. 
14 D. Pajuelo et al.

A. A monolayer of granulocytes was infected at a moi of 10 , and the cells were examined under an inverted microscope at 90 min after infection.

B. The same samples as in (A) but stained with Hemacolor (Millipore) at $60 \mathrm{~min}$. A, control; B, CECT4999; C, $\Delta$ vep20. Bar, $5 \mu \mathrm{M}$.

Fig. S2. Microscopic observation of the cytopathic effects of V. vulnificus strains. The bacteria were incubated with eel erythrocytes at a moi of 10 for $90 \mathrm{~min}$.

A. Control.

B. CECT4999.

C. $\Delta$ vep20. Bar, $100 \mu \mathrm{M}$.

Fig. S3. Time course analysis of the transcript/RNA levels of vep20 using qRT-PCR. Transcript/RNA levels of vep20 expressed as the fold induction in CECT4999 cultured in CM9-Tf (A) or CM9-EP (B) measured using qRT-PCR (solid line) versus CECT4999 growth measured as $\mathrm{OD}_{600}$ (dashed line) at the indicated time points.

Fig. S4. Molecular phylogenetic analysis of vep20 using the Maximum Likelihood method based on the Tamura-Nei model. The vep20 sequence types are represented. The bootstrap support values are indicated in the corresponding nodes as percentages. The tree is drawn to scale, with branch lengths measured as the number of substitutions per site.

Table S1. Primers used in this study.

Table S2. Four independent (A; B; C; D) protein identifications through LC-MS/MS.

Appendix S1. DNA sequences. 